\title{
Towards Enhancing Access of HIV/AIDS Healthcare Information in Tanzania: Is a Mobile Application Platform a Way Forward?
}

\author{
Ibrahim A. Mwammenywa \\ Nelson Mandela - African Institution of Science and Technology, P. O. Box 447, Arusha, Tanzania. \\ The University of Dar es Salaam, P. O. Box 35131, Dar es Salaam, Tanzania \\ E-mail: mwammenywai@nm-aist.ac.tz or a.m.ibra90@gmail.com \\ Shubi F. Kaijage \\ Nelson Mandela - African Institution of Science and Technology, P. O. Box 447, Arusha, Tanzania. \\ E-mail: shubi.kaijage@nm-aist.ac.tz
}

Received: 29 May 2018; Accepted: 20 June 2018; Published: 08 July 2018

\begin{abstract}
This survey study evaluates the peoples' acceptance and comfortability on accessing the HIV/AIDS healthcare information through visiting HIV/AIDS Care and Treatment Centers (CTCs). Furthermore, the survey examines whether a mobile application platform can be the way forward towards enhancing HIV/AIDS healthcare information delivery in Tanzania. This study was conducted in Dar es Salaam city in Tanzania. The structured questionnaire-based survey was carried-out involving a total of 208 respondents, among them, 45 were the HIV/AIDS healthcare practitioners. The collected data were analyzed by using WEKA and Python computer programming software. The study findings indicated that: $24.5 \%$ of the respondents claimed that they were not comfortable going to HIV/AIDS CTCs indicating that they were afraid of being exposed and stigmatized; almost one-third (31.3\%) of respondents prefer to seek HIV/AIDS related information from online sources; $78.5 \%$ of respondents preferred to have an official mobile application for access the HIV/AIDS healthcare information; $64.4 \%$ of HIV/AIDS practitioners indicated the need of having a mobile application platform for HIV/AIDS healthcare information delivery; and more than two-third of HIV/AIDS practitioners claimed to be able to serve people with HIV/AIDS healthcare information online. It is concluded that there is a need for the HIV/AIDS healthcare providers to have a mobile application platform for HIV/AIDS healthcare information delivery. The mobile application platform will consequently help people to confidentially access the HIV/AIDS healthcare information in their mobile electronic gadgets frequently without fear of being exposed as if they would frequently visit CTCs.
\end{abstract}

Index Terms-HIV/AIDS, Mobile Health (m-health), Mobile Application, HIV/AIDS Healthcare Information, Online HIV/AIDS Healthcare Information.

\section{INTRODUCTION}

Since being discovered, Human Immunodeficiency Virus infection and Acquired Immunodeficiency Syndrome (HIV/AIDS) has been one of the most killing global pandemics to date. Fighting the HIV/AIDS has been a very daunting challenge in the global health and particular Sub-Saharan African (SSA) countries. Approximately of 36.7 million people were living with HIV worldwide by 2015, with more than two-third of them living in SSA. Tanzania in particular, there were about 1.4 million people living with HIV (PLHIV), and around 36,000 deaths which occurred in 2015 were due to HIV/AIDS [1]. The most of SSA governments, such as the Tanzanian government, have taken the socio-political and economic measures to tackle the HIV pandemic by providing free HIV medical services such as provision of the Antiretroviral therapy (ART) in the public hospitals [2]. Approximately, 10.3 million (about 54\%) of PLHIV were accessing ART in eastern and southern SSA [1].

Despite these measures undertaken by the government in providing free HIV medical services such as ART in the public hospitals, the fear of stigma and lack of awareness is still a handicap. The fear of stigma is still holding some people in the society from freely going to the HIV/AIDS Care and Treatment Centers (CTCs) to receive the HIV/AIDS healthcare clinical services including HIV/AIDS healthcare information [3-5]. [3] described that among different factors for fear of stigma among PLHIV, $37.4 \%$ fear for unethical treatment of PLHIV and $31.1 \%$ for unofficial disclosure of their health status. The timely access to the relevant HIV/AIDS healthcare information can help people in making informed decisions of living a healthy life [6, 7]. The living of healthy life includes the change behavior, increase ability to self-care and more committed to treatment with more life hope and empowerment. 
However, the Information and Communication Technologies (ICT) provides a great potential in delivery of health services. The usage of mobile technology has been of different forms such as mobile health (m-health), mobile money transactions (for example M-Pesa), and mobile banking. The m-health has integrated users in health associated activities, and thus improving availability of healthcare services, health information, and influencing healthy user behavior [8]. There is a massive increase in usage of mobile communication and internet in Tanzania showing $80 \%$ mobile phones penetration as well $40 \%$ internet penetration [9].

This paper reports the assessment on the people's general awareness and comfortability towards physically attending HIV/AIDS CTCs for accessing the HIV/AIDS healthcare information. Moreover, this study assesses whether the use of ICT in form of mobile application can be a way forward for delivering the HIV/AIDS healthcare information for broader coverage (to many people with an easy access) without exposing them.

The rest of this paper is organized as follows: the second section explains the background information on the currently situation in provision of HIV/AIDS healthcare information and the fear of stigma as its major challenge. The third section talks about related works of which the mobile technologies have been applied to facilitate the delivery of healthcare information. The detailed research study design and methods used from the data collection, data analysis to results presentation have been explained in section four. Sections five and six provide the detailed explanation of results and discussion respectively. The conclusion has been drawn in section seven. Finally, the limitations of this study were given in section eight.

\section{BACKGROUND}

Currently in Tanzania, all of the HIV/AIDS healthcare service are offered at the CTCs across the country. The HIV/AIDS healthcare services ranges from provision of general public HIV/AIDS education, HIV testing, HIV counselling to HIV patient treatment and medications (including the provision of antiretroviral, ARV drugs). However, fear of being identified and/or stigmatized is still holding a lot of people in the society from freely going to CTCs for these HIV/AIDS healthcare services [3-5].

This research study is trying to assess whether the usage of mobile application platform can be a comfortable and acceptable way for people to access the HIV/AIDS healthcare information services. The usage of a confidential mobile application platform without actual regular visits to the CTCs may help people who want to access the HIV/AIDS healthcare information but do afraid of being identified and stigmatized.

HIV/AIDS healthcare information is any sort of HIV/AIDS related information which should be shared to the general public or a particular client ${ }^{1}$. There are different types of healthcare information such as appointment and medication reminders, general health tips, diagnostic information, symptoms and vital signs [10]. The important healthcare information which are provided in the HIV/AIDS CTCs are HIV/AIDS healthcare tips, HIV/AIDS healthcare recommendations, HIV/AIDS personal clinical counselling or consultation between the client and HIV/AIDS practitioner. These services are to remain as the key services even when the HIV/AIDS healthcare information delivery is through the mobile application platform.

\section{RELATED WORKS}

In ICT, the mobile technology is the technology used for transferring of a specific information from one part to the intended recipient (or recipients) by using the cellular communication system. Currently, the mobile technology has been widely used for accessing and dissemination of information in various sectors such health, finance, and security and control systems. Mobile application is a software which makes the use of the mobile technology, and it is used within mobile devices such as mobile phones. Mobile application allows mobile gadget users to interact with each other or with different online service providers $[11,12]$.

The health sector has been actively employing the mobile technology in delivering health services to the public. The usage of the mobile technology applications for healthcare provisions is known as mobile health (or m-health) [13]. M-health involves the transfer of healthcare resources including the delivery of healthcare information by using the mobile electronic means [14]. Mobile health applications have been growing so fast recently, this is due to its contribution in shifting behavior to strengthen disease prevention at the low cost of acquiring a quality healthcare services $[8,13,15,16]$.

In Tanzania, like other African countries, the number of mobile solutions using mobile applications for different healthcare services is growing very fast. These mobile applications cover healthcare services such as dissemination of nutrition services and maternal healthcare with example of Mobile Alliance for Maternal Action (MAMA), NutriMobile and Healthy Pregnancy, Healthy Baby (HPHB) [17-19]. However, there is no any mobile application platform for dissemination of HIV/AIDS healthcare information in Tanzania to date. [6] made a call for online dissemination of HIV/AIDS healthcare information since there is a considerably people's high effort to try to access to internet-based HIV information, HIV/AIDS clinical tips and recommendations.

\section{METHODOLOGY}

The questionnaire-based study was conducted among

${ }^{1}$ Client - A person who is accessing the HIV/AIDS health care services such as healthcare tips, recommendations, and/or clinical conversation. 
different groups of people, involving people living with HIV (PLHIV), and those without HIV along with the HIV medical practitioners. This study was based in Dar es Salaam city in Tanzania. Dar es Salaam was chosen as it indicated high levels of stigma per PLHIV about 49.7 percent as compared to 39.4 percent from other regions [20]; while having a high HIV prevalence of about 11 percent [21]. Moreover, Dar es Salaam is the largest and most developed city as far as ICT infrastructures is concerned, in addition to the highest usage of internet and mobile services in the country [22, 23]. The region contains four large district referral hospitals namely Mwananyamala Hospital, Temeke Hospital, SinzaPalestina Hospital and Infectious Diseases Centre (IDC) each found in Kinondoni, Temeke, Ubungo and Ilala districts respectively. These hospitals have special HIV/AIDS related clinics to offer HIV/AIDS healthcare clinical services such as general public HIV/AIDS healthcare information, counseling, testing and continued adherence counseling, medical treatment of PLHIV including treatment of opportunistic infections and provision of antiretroviral (ARV) drugs.

Due to complexity of this study, both people getting HIV/AIDS healthcare clinical services and HIV/AIDS medical practitioners in these hospitals were involved in this study. The study was extended to involve the HIV/AIDS medical practitioners of a Non-Government Organization (NGO) dealing with HIV/AIDS services in remote areas within Dar es Salaam region, named Pastoral Activities and Services for people with AIDS in Dar es Salaam Archdiocese (PASADA). The data from respondents were used to assess the need of mobile application for accessing HIV/AIDS healthcare information. The data from HIV/AIDS medical practitioners were used in assessment of capacity and readiness of the HIV practitioners to serve people with the HIV/AIDS healthcare information online.

The sample size was determined by using Kish formula for cross-sectional studies [24, 25]. The calculation based on the HIV prevalence in Dar es Salaam of 11 percent and the entire population of the region of about 5,781,557 people at the precision of 5 percent and confidence level of 95 percent $[21,26]$. Therefore, the minimum sample size was found to be 151 people. The study involved random sampling of both male and female who filled in questionnaire on their consent. The questionnaires were made of three parts; demographic information (such as gender, age, education level and mobile phones ownership), comfortability and attendance to HIV/AIDS CTCs, and finally the perception towards accessing the HIV/AIDS healthcare information online. All of the questions in the mentioned parts were independent. The dependent variable evaluated whether respondents would want the mobile application platform for accessing HIV/AIDS healthcare information.

The internal-consistency of the HIV/AIDS practitioners' readiness towards providing the HIV/AIDS healthcare information online were assessed using the Cronbach's alpha coefficient. Cronbach's alpha coefficient is used for examination of internal reliability and interrelation among the contributing items. The study had an alpha coefficient within accepted range of value is above 0.7 [27, 28].

The collected data were analyzed by using Python, computer programing software for big data [29]. The study employed the hierarchical regression analysis which was performed by using data mining and analysis software, WEKA version 3.8.1 [30]. The hierarchical regression analysis was performed to examine the effect of different factors towards the need of mobile application platform for accessing HIV/AIDS healthcare information. This method was selected due to its suitability in investigating the impact of several independent variables sequentially [31]. Furthermore, [32 proved that this is an appropriate technique for evaluating the influence of control independent factors to a dependent issue. This analysis involved four steps/models of regression analysis. In the first step, only the demographic attributes were examined towards the respondents' need of mobile application for accessing HIV/AIDS healthcare information. The second step added the respondents' mobile phones ownership, in third step the general awareness and attendance to CTCs were considered. Final stage examined if the prior access of any health information through mobile and online media was to influence into the need of mobile application for accessing HIV/AIDS healthcare information.

\section{RESULTS}

In this study, total of 208 people participated, among them, 45 were HIV/AIDS practitioners.

\section{A. Demographic Characteristics of Respondents.}

Out of 163 respondents who were not HIV/AIDS practitioners, number of male respondents were slightly higher $(51.5 \%)$ than female respondents. Within this group of respondents, majority were aged between $20-$ 29 years (about 46\%). Majority of the respondent who were willing to participate in this study had the tertiary education (36.2\%). Table 1 shows demographic characteristics of all respondents.

Table 1. Demographic Characteristics of Respondents

\begin{tabular}{cccc}
\hline Demographic Characteristics & Respondents & $\begin{array}{c}\text { Percentage } \\
(\mathbf{\%})\end{array}$ \\
\hline \multirow{2}{*}{ Gender } & Male & 84 & 51.5 \\
& Female & 79 & 48.5 \\
& $15-19$ & 14 & 8.6 \\
Age & $20-29$ & 75 & 46.0 \\
(in Years) & $30-39$ & 31 & 19.0 \\
& $40-49$ & 26 & 16.0 \\
& $50-59$ & 14 & 8.6 \\
& 60 and above & 3 & 1.8 \\
Education & Non-formal education & 9 & 5.5 \\
& Primary education & 41 & 25.2 \\
& Secondary education & 54 & 33.1 \\
& Tertiary education & 59 & 36.2 \\
\hline
\end{tabular}




\section{B. Mobile Phones Ownership}

Among the respondents, only $9.2 \%$ do not own any mobile phone, while a total of $60.8 \%$ of all respondents had at least one smart-phone with internet capabilities. Detailed information on the ownership distribution of mobile phones among the respondents is depicted in Fig. 1 below.

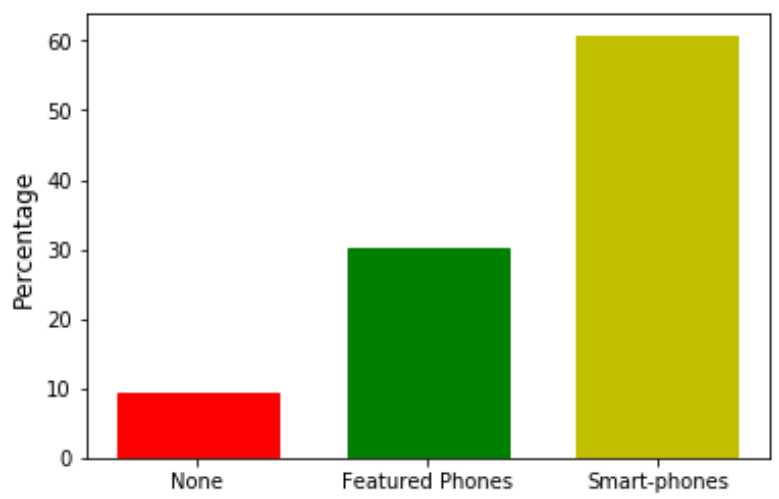

Fig.1. Mobile Phones Ownership Distribution

\section{Respondents' Awareness and Comfortability towards Attending HIV/AIDS CTCs}

Only $88.3 \%$ of respondents are aware of the existence of HIV/AIDS CTCs. Furthermore, even fewer respondents $(60.7 \%)$ had at least once visited the HIV/AIDS CTCs to seek for HIV/AIDS healthcare information. $24.5 \%$ of the respondents were not comfortable going to HIV/AIDS CTCs indicating that they were afraid of being exposed and stigmatized. This situation is well summarized by Fig. 2 below.

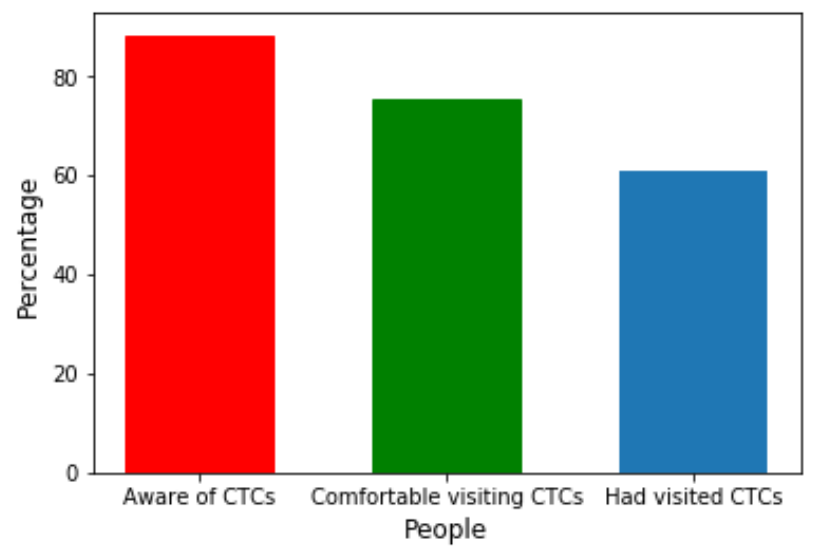

Fig.2. Comparison of peoples' awareness, comfortability and actual visiting HIV/AIDS CTCs

\section{HIV/AIDS Healthcare Information Seeking Pattern}

Almost one-third $(31.3 \%)$ of respondents prefer to seek HIV/AIDS related information from online media (via internet). However, $33.7 \%$ of the respondents claimed to get the HIV/AIDS healthcare information through visiting to HIV/AIDS CTCs. Fig. 3 below provides HIV/AIDS healthcare information seeking pattern as analyzed from the respondents.

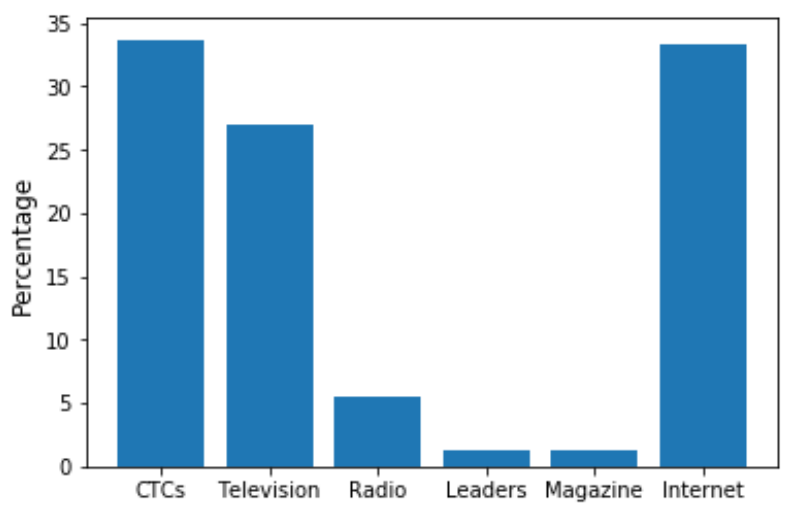

Fig.3. HIV/AIDS Healthcare Information Access Pattern

\section{E. Towards Accessing HIV/AIDS Healthcare Information Online}

Almost two-third of the respondents $(66.3 \%)$ had the tendency of accessing and searching of different health information through online media sources. Furthermore, $79.1 \%$ of respondents believed that they could access reliable HIV/AIDS healthcare information if there is an online platform while $78.5 \%$ went even further by suggesting that they wanted the mobile application platform. This information is summarized in table 2 below.

Table 2. Towards Accessing HIV/AIDS Healthcare Information Online

\begin{tabular}{lcc}
\hline & $\begin{array}{c}\text { Respon } \\
\text { dents }\end{array}$ & $\begin{array}{c}\text { Percentage } \\
(\%)\end{array}$ \\
\hline $\begin{array}{l}\text { I access and search for different } \\
\text { healthcare information through } \\
\text { online sources }\end{array}$ & 99 & 66.3 \\
$\begin{array}{l}\text { I believe that I can access reliable } \\
\text { HIV/AIDS healthcare information } \\
\text { in online platform }\end{array}$ & 129 & 79.1 \\
$\begin{array}{l}\text { I would like to have a mobile } \\
\text { application for accessing the }\end{array}$ & 128 & 78.5 \\
\hline HIV/AIDS healthcare information & & \\
\hline
\end{tabular}

F. Factors Contributing to the need of Mobile Application Platform for HIV/AIDS Healthcare Information Access

In examining why respondents asked for the mobile application platform for accessing the HIV/AIDS healthcare information, different factors were put into consideration. The study employed the hierarchical regression analysis to assess the proportional contribution of different factors towards the need of mobile application platform for accessing HIV/AIDS healthcare information. The findings showed that demographic factor contributed $3.25 \%$ in need of mobile application platform for accessing HIV/AIDS healthcare information. The ownership of mobile phone contributed further to $7.28 \%$ for respondents to need this mobile application platform. However, the general awareness and attendance to CTCs had a very small negative influence towards the need of the mobile application platform, reducing the overall contribution to $7.26 \%$ as shown in model 3 . 
Moreover, the experience of using other health-related mobile application proved to have almost negligible contribution to the respondents need for mobile application platform for accessing HIV/AIDS healthcare information. Table 3 below narrates hierarchical regression analysis of factors affecting contribution to the need of the mobile application for accessing HIV/AIDS healthcare information.

Table 3. Hierarchical Regression Analysis

\begin{tabular}{|c|c|c|c|c|}
\hline Factors & Model 1 & Model 2 & Model 3 & Model 4 \\
\hline Gender & 0.0002 & 0.0002 & $\sim 0.0001$ & $\sim 0.0001$ \\
\hline Increasing Age & 0.0004 & 0.0003 & -0.0001 & 0.0001 \\
\hline $\begin{array}{c}\text { Increasing } \\
\text { Education Level }\end{array}$ & 0.0882 & 0.0621 & 0.0601 & 0.0502 \\
\hline $\begin{array}{l}\text { Having a Mobile } \\
\text { Phone }\end{array}$ & & 0.2962 & 0.2752 & 0.2762 \\
\hline $\begin{array}{c}\text { Having a Smart } \\
\text { Phone }\end{array}$ & & 0.0003 & 0.0002 & 0.0002 \\
\hline $\begin{array}{l}\text { Knowing HIV } \\
\text { CTCs }\end{array}$ & & & -0.0052 & -0.0032 \\
\hline Going to CTCs & & & -0.0102 & -0.0022 \\
\hline $\begin{array}{l}\text { Frequency of } \\
\text { going to CTCs }\end{array}$ & & & -0.0091 & -0.0065 \\
\hline $\begin{array}{l}\text { Comfortability } \\
\text { going to CTCs }\end{array}$ & & & -0.0105 & -0.0102 \\
\hline $\begin{array}{l}\text { Experience of } \\
\text { using m-Health } \\
\text { applications }\end{array}$ & & & & $\sim 0.0001$ \\
\hline$D f^{2}$ & 3 & 5 & 9 & 10 \\
\hline $\begin{array}{l}\text { Adjusted R- } \\
\text { squared }^{3}\end{array}$ & 0.0325 & 0.0728 & 0.0726 & 0.0726 \\
\hline
\end{tabular}

Notes: All figures were round off to 4 decimal places and $\mathrm{P}<0.05$

\section{G. HIV/AIDS Practitioners}

The study also collected information from among 45 HIV/AIDS practitioners. Majority of them, almost onefifth $(22.2 \%)$ were from Infectious Diseases Centre (IDC) which is a special Care and Treatment Center for people living with HIV (PLHIV) in Dar es Salaam. Majority $(71.1 \%)$ were serving more than 30 people per day on more or less same kind of clinical services. Table 4 shows the distribution of HIV/AIDS healthcare practitioners who were involved in this study.

Table 4. HIV/AIDS Healthcare Practitioners

\begin{tabular}{llcc}
\hline & Practiti & $\begin{array}{c}\text { Percentag } \\
\text { oners }\end{array}$ \\
\hline & Temeke Hospital & 8 & 17.8 \\
HIV/AIDS & Mwananyamala Hospital & 8 & 17.8 \\
CTC & Sinza Hospital & 7 & 15.6 \\
& IDC & 10 & 22.2 \\
& Kairuki Hospital & 7 & 15.6 \\
& PASADA & 5 & 11.1 \\
Number of & Less than 5 & 1 & 2.2 \\
People & 5 to 10 & 5 & 11.1 \\
served per & 10 to 20 & 4 & 8.9 \\
day by each & 20 to 30 & 3 & 6.7 \\
practitioner & More than 30 & 32 & 71.1 \\
\hline
\end{tabular}

${ }^{2} D f$ : Degree of Freedom - number of independent variables in the statistical analysis.

${ }^{3}$ Adjusted $R$-squared: It calculates R-square values (how much variance is in a model) from significant independent variables in the model

\section{H. HIV/AIDS Practitioners' Perspectives on Provision of} HIV/AIDS Healthcare Information

Table 5 narrates that out of 45 HIV/AIDS practitioners, $91.1 \%$ insisted that it is important to always provide the HIV/AIDS healthcare information to people in the society. About three-fifth (62.2\%) acknowledged the existing effort of disseminating the HIV related information to the society but insisted on more effort should be employed. Surprisingly, more than half $(55.6 \%)$ of HIV/AIDS practitioners cited that they did not disseminate the HIV related healthcare information. Four-fifth of the respondents in this category agreed that the said healthcare information can be transacted via electronic means, while $64.4 \%$ went further by showing there is a need for having a mobile application platform for delivering the HIV/AIDS healthcare information.

Table 5. HIV/AIDS Practitioners' Perspectives on Provision of HIV/AIDS Healthcare Information

\begin{tabular}{|c|c|c|}
\hline & Practitioners & $\begin{array}{c}\text { Percentage } \\
(\%)\end{array}$ \\
\hline $\begin{array}{l}\text { It is important to disseminate } \\
\text { HIV/AIDS healthcare information } \\
\text { to society }\end{array}$ & 41 & 91.1 \\
\hline \multirow{4}{*}{$\begin{array}{l}\text { Is HIV/AIDS } \\
\text { healthcare } \\
\text { information } \\
\text { reaching } \\
\text { community? }\end{array}$} & 8 & 17.8 \\
\hline & 9 & 20 \\
\hline & 28 & 62.2 \\
\hline & 0 & 0 \\
\hline $\begin{array}{l}\text { I can provide the HIV/AIDS } \\
\text { healthcare information using online } \\
\text { platform }\end{array}$ & 36 & 80 \\
\hline $\begin{array}{l}\text { There is a need of having a mobile } \\
\text { application platform for delivering } \\
\text { HIV/AIDS healthcare information }\end{array}$ & 29 & 64.4 \\
\hline
\end{tabular}

\section{HIV/AIDS Practitioners' Readiness towards Online} Delivery of HIV/AIDS Healthcare Information

Two-third of the HIV/AIDS practitioners said that they are computer literate and even have the internet access at their offices at the CTCs. However, only one-third of them are supplied with the working computers in their offices. Cronbach's alpha coefficient of 0.7012 shows that there is an internal reliability and interrelation for them to be ready to offer the HIV/AIDS services online.

Table 6. HIV/AIDS Practitioners' Readiness towards Online Delivery of HIV/AIDS Healthcare Information

\begin{tabular}{|c|c|c|c|}
\hline & Practitioners & $\begin{array}{c}\text { Percentage } \\
(\%)\end{array}$ & $\begin{array}{c}\text { Cronbach's } \\
\text { alpha }\end{array}$ \\
\hline $\begin{array}{l}\text { HIV/AIDS } \\
\text { Practitioners' } \\
\text { Readiness }\end{array}$ & & & 0.7012 \\
\hline $\begin{array}{l}\text { Do you have } \\
\text { computer } \\
\text { knowledge? }\end{array}$ & 35 & 77.8 & \\
\hline $\begin{array}{l}\text { Does your Office } \\
\text { have Working } \\
\text { Computer? }\end{array}$ & 15 & 33.3 & \\
\hline $\begin{array}{l}\text { Does your Office } \\
\text { have Internet } \\
\text { Access? }\end{array}$ & 33 & 73.3 & \\
\hline
\end{tabular}




\section{DISCUSSION}

The findings of this study show that currently majority of people still rely on accessing HIV healthcare information through having direct personal contacts with HIV/AIDS practitioners by visiting HIV/AIDS CTCs. In the same way, previous different studies revealed that PLHIV mostly relied on direct contact with HIV/AIDS healthcare practitioners to access the HIV/AIDS health information [33-35].

The study reveals that majority of people are aware of existence of HIV/AIDS CTCs found in different public and private hospitals. However, not all people who are aware of these HIV/AIDS CTCs are comfortable and ready to visit them for accessing the HIV/AIDS related information. A significant portion of people indicated that they are not comfortable visiting them, citing that they are scared of being exposed and/or stigmatized. These findings support a number of previous studies which showed that fear of stigma is still among the challenges in delivery of HIV/AIDS healthcare information [3-5]. Furthermore, [3] described that among different factors for fear of stigma among PLHIV, 37.4 percent fear for unethical treatment of PLHIV and 31.1 percent for unofficial disclosure of their health status.

Moreover, this study finds that there is a massive increase in number of people who seek the HIV/AIDS related information from the internet sources. [6] stipulated that there is a considerably people's high effort to access to internet-based HIV information. Some previous studies indicated that Internet technologies improvements have vastly increased access of healthcare information [36-39]. This could be highly contributed by the massive increase in penetration and usage of Internet services, and mobile phones as well [9, 40]. Additionally, this study evidently shows that majority of people own mobile phones and in particular at least one smart phone. These findings are in line with the communication statistical report of December 2017, which shows a massive increase in usage of mobile communication and internet access penetration of equivalent to 80 percent and 40 percent respectively [9, 40]. Surprisingly, this study shows that the usage of the tradition ICT such as radio for accessing the HIV/AIDS health information has sharply diminished. This is in contrary to previous studies, which indicated the majority of people depended on the healthcare information from personal contacts at the HIV/AIDS CTCs and through radio programs [33, 41-43].

Furthermore, the study reveals that majority of people believed that they could access reliable HIV/AIDS healthcare information through the mobile application platform. The study reveals that the education level and ownership of mobile phones have played a significant role in influencing people's need for mobile application platform. The need of having a mobile application platform for HIV/AIDS healthcare information delivery was even supported by the HIV/AIDS healthcare practitioners during this study. In additional, the study findings have particularly shown that majority of the HIV/AIDS healthcare practitioners have the capacity to provide the HIV/AIDS healthcare information through online means. However, the lack of computer facilities in some of their healthcare centers is still a challenge.

\section{CONCLUSION}

This study has found that the ever-growing usage of mobile telephony and particularly internet can be useful for HIV/AIDS healthcare information delivery. Majority of people who participated in this study suggested that there is a need of having a mobile application platform for HIV/AIDS healthcare information delivery. This need was even supported by the HIV/AIDS healthcare practitioners with this very study. The HIV/AIDS healthcare practitioners also implied there is a need for having a mobile application platform for disseminating HIV/AIDS healthcare information; and even suggesting that they were ready to offer this service online.

The study findings imply that the usage of ICT, especially the mobile technology is essential in providing the healthcare information. The mobile application platform will consequently help people to confidentially access the HIV/AIDS healthcare information in their mobile electronic gadgets frequently without fear of being exposed as if they would frequently visit CTCs. This subsequently improve the time and quality access to the healthcare information; and inspiring the change of behavior to strengthen disease prevention. Specifically, dissemination of HIV/AIDS healthcare information must line up the use of internet and mobile phones for broader coverage and impact. This usage of mobile health (mhealth) technology is important especially in this communication era where by the majority own mobile gadgets with internet capabilities.

Healthcare providers, the ministry of health and all other stakeholders in fighting against HIV/AIDS should work on these findings and therefore develop a mobile application for HIV/AIDS healthcare information delivery. The mobile application platform developed should be made aware to the public in order to easy their hustle of seeking HIV/AIDS healthcare information. The developed mobile application platform should be simple, user friendly and available in local language, such as Kiswahili in Tanzania. Since the personal medical information is very sensitive data, this research recommends that the developed mobile application platform should handle the personal healthcare and healthcare information with maximum confidentiality.

\section{STUDY LIMITATIONS}

This study considered only respondents whom with their consent were mentally and physically free and ready to participate. The study excluded people who were hesitant and those who indicated negative attitude towards this kind of studies, this was done to avoid responses which are not genuine. The study also excluded the critically sick people whom might be influenced by the health situations. Future studies should emphasize on 
assessment of the impact of the online provision of the HIV/AIDS healthcare information; and make the comparison with the impact of accessing the same information through visiting the traditional HIV/AIDS CTCs. The future studies can also consider to have a modified research design that can comprise of both qualitative and quantitative methods in order to have a concrete description of study and their findings.

\section{ACKNOWLEDGMENT}

The authors wish to thank Dr. Richard Z. Adam and Dr. Sam Makala for facilitating the data collection in the HIV/AIDS CTCs. This study was partially financed by the German Academic Exchange Service (DAAD).

\section{REFERENCES}

[1] The Joint United Nations Programme on HIV/AIDS, "Global HIV Statistics," 2016. Retrieved from www.unaids.org/sites/default/files/media_asset/globalAIDS-update-2016_en.pdf [Accessed on October 25, 2017].

[2] J. Bor, A. J. Herbst, M. L. Newell, T. Barnighausen, "Increases in Adult Life Expectancy in Rural South Africa: Valuing the Scale-Up of HIV Treatment," Science, 339 (6122), 961-965, 2013. DOI: 10.1126/science. 1230413

[3] G. T. Feyissa, L. Abebe, E. Girma, M. Woldie, "Stigma and Discrimination Against People Living with HIV By Healthcare Providers, Southwest Ethiopia," BMC Public Health, 2012, 12, 522. DOI: 10.1186/1471-2458-12-522

[4] N. C. Mbonu, B. van den Borne, N. K. De Vries, "Stigma of People with HIV/AIDS in Sub-Saharan Africa: A Literature Review," Journal of Tropical Medicine, 2009, 1-14. DOI: $10.1155 / 2009 / 145891$

[5] M. Saki, S. M. K. Kermanshahi, E. Mohammadi, M. Mohraz, "Perception of Patients With HIV/AIDS from Stigma and Discrimination," Iranian Red Crescent Medical Journal, 17(6), 2015, e23638. DOI: 10.5812/ircmj.23638v2

[6] E. T. Lwoga, T. Nagu, A. S. Sife, "Online HIV Information Seeking Behavior Among People Living with HIV in Selected Tanzanian Public Hospitals," Journal of Systems and Information Technology, Vol. 19 Issue: 1/2, pp.94-115, 2017. DOI: 10.1108/JSIT-06-2016-0038

[7] F. Zare-Farashbandi, A. Lalazaryan, "A Review of Models and Theories of Health Information Seeking Behavior," International Journal of Health System and Disaster Management, 2014, 2(4), 193. DOI: 10.4103/2347-9019.144371

[8] R. van Genuchten, W. Haring, D. van Kassel, K. Yakubi, "Mobile-phone Use in Tanzania," TAN2012 Mark. Res. 2012.

[9] TCRA (Tanzania Communications Regulatory Authority), "Communication Report of June 2017." https://www.tcra.go.tz/images/documents/telecommunicat ion/TelCom-Statistics-June-2017.pdf [Accessed on November 27, 2017].

[10] K. J. Serrano, et al., "Willingness to Exchange Health Information via Mobile Devices: Findings from a Population-Based Survey," Ann Fam Med, 2016, 14(1), 34-40. DOI: $10.1370 / \mathrm{afm} .1888$

[11] J. Muthee, N. Mhando, "AMDI-BBC Summary Report," African Media Dev. Initiat. 2006.

[12] R. Meier, "Professional Android 2 Application Development" 2010.
[13] C. Z. Qiang, M. Yamamichi, V. Hausman, R. Miller, D. Altman, "Mobile Applications for the Health Sector," 2012.

[14] WHO, "mHealth: New Horizons for Health Through Mobile Technologies" World Health Organization, 2011.

[15] H. Cole-Lewis, T. Kershaw, "NIH Public Access," Epidemiol Rev, 2011, 32(1), 56-69. DOI: 10.1093/epirev/mxq004.

[16] P. Mechael, et al.,"Barriers and Gaps Affecting mHealth in Low and Middle Income Countries," Policy White Paper, 2010

[17] MAMA (Mobile Alliance for Maternal Action), "Global Monitoring and Evaluation Framework," 2012. [Online]. Available at: http://www.mobilemamaalliance.org/sites/default/files/M AMA_Global_MEPlan_FINAL_all.pdf. [Accessed: 5May-2018].

[18] GSMA, "Mobile for Development, mHealth Country Feasibility Report: Tanzania," 2014. Available at: http://tanzania.gsmamhealthfeasibility.com/GSMA_mHea 1th_Country_Feasibility_Report_Tanzania_2015.pdf. [Accessed: 26-May-2018].

[19] N. Mduma, K. Kalegele, "An Integrated Mobile Application for Enhancing Management of Nutrition Information in Arusha Tanzania," International Journal of Computer Science and Information Security (IJCSIS), Vol 13, No. 7, pp 34-38. 2015.

[20] NACOPHA" The People Living with HIV Stigma Index Report, (December 2015)." Retrieved from http://www.stigmaindex.org/sites/default/files/reports/Tan zaniaSTIGMA INDEX REPORT - Final Report pdf.pdf

[21] L. V Mutasingwa, S. K. Mbirigenda, "Investigating Risky Sexual Behaviors among Youth in the Context of the HIV Epidemic in Mbeya Region, Tanzania," (March 2017). 2017.

[22] Ministry of Communications and Transport (The United Republic of Tanzania), "National Information and Communications Technologies Policy, (March 2003)." Retrieved from http://unpan1.un.org/intradoc/groups/public/documents/un pan/unpan033693.pdf [Accessed: 26-May-2018].

[23] P. Esselaar, O. Hesselmark, T. James, J. Miller, "Country ICT Survey for Tanzania: Final Report." 2001.

[24] L. Kish, "Survey Sampling," New York: Wiley Interscience Publication. 1965.

[25] W. W. Daniel, "Biostatistics: A foundation for analysis in the health sciences," 7th Edition, John Wiley \& Sons, Inc., Hoboken. 1999.

[26] NBS (National Bureau of Statistics), "Tanzania Total Population by District - Regions - 2016-2017." http://www.nbs.go.tz/nbstz/index.php/english/statisticsby-subject/population-and-housing-census/844-tanzaniatotal-population-by-district-regions-2016 [Accessed: 26June-2018].

[27] L. J. Cronbach, "Coefficient Alpha and the Internal Structure of Tests" Psychometrika, 1951, 16(3), 297-334. DOI: 10.1007/BF02310555

[28] M. Tavakol, R. Dennick, "Making Sense of Cronbach's Alpha," International Journal of Medical Education, 2011 2,53

[29] W. McKinney, "Wpython for Data Analysis: Data Wrangling with Pandas, Numpy, And Ipython," O'Reilly Media, Inc. 2012.

[30] J. Han, J. Pei, M. Kamber, "Data Mining: Concepts and Techniques" Elsevier. 2011

[31] J. V. Petrocelli, "Hierarchical Multiple Regression in Counseling Research: Common Problems and Possible 
Remedies," Measurement and Evaluation in Counseling and Development, 2003, 36, 9-22.

[32] A. Chong, F. F. T. S. Chan, K. K. B. Ooi, "Predicting Consumer Decisions to Adopt Mobile Commerce: Cross Country Empirical Examination Between China and Malaysia," Decision Support Systems, 2012, 53(1), 34-43. DOI: 10.1016/j.dss.2011.12.001

[33] S. F. Rumisha, et al., "Community Knowledge and Information Communication Gaps on HIV/AIDS in Iringa Municipality Tanzania," Tanzania Journal of Health Research, 2006, 8(2), 101-108. DOI: 10.4314/thrb.v8i2.14281

[34] L. Mboera, et al., "Knowledge and Health Information Communication in Tanzania," East African Journal of Public Health, 2007. Retrieved from https://www.ncbi.nlm.nih.gov/pubmed/17907759 [Accessed: 26-May-2018].

[35] R. O. Mwaiswelo, J. R. Masalu, "Oral Health Knowledge and Behavior Among Pregnant Women in Kyela District, Mbeya, Tanzania," Tanzania Dental Journal, 2008, 14(2), 47-52. DOI: 10.4314/tdj.v14i2.37570

[36] S.C. Kalichman, et al., "Internet Access and Internet Use for Health Information Among People Living With HIVAIDS," Patient Education and Counseling, 2002, 46(2), 109-16. Retrieved from http://www.ncbi.nlm.nih.gov/pubmed/11867240 [Accessed: 16-March-2018].

[37] S.C. Kalichman, et al., "Internet Use Among People Living With HIV/AIDS: Coping and Health-Related Correlates," AIDS Patient Care and STDs, 2005, 19(7), 439-48. DOI: 10.1089/apc.2005.19.439

[38] C. R. L. Boot, F. J. Meijman, "The Public and The Internet: Multifaceted Drives for Seeking Health Information," Health Informatics Journal, 2010, 16(2), 145-56. DOI: $10.1177 / 1460458210364786$

[39] S. J. Chang, E. O. Im, "A Path Analysis of Internet Health Information Seeking Behaviors Among Older Adults," Geriatric Nursing, 2014, 35(2), 137-141. DOI: 10.1016/j.gerinurse.2013.11.005

[40] Internet World Stats, "Africa Internet Usage, Facebook and Population Statistics.” Retrieved December 23, 2017, from http://www.internetworldstats.com/stats1.htm

[41] W. Chilimo, J. Nawe, "The Role of Nutritional Information in Addressing Under-Five Child Malnutrition in Tanzania," University of Dar es Salaam Library Journal, 2004, 5(2), 82-92. DOI: 10.4314/udslj.v5i2.26611

[42] B. D. Montez, "Identifying Health Information Needs in Tanzania: Evidence from The Audience Scapes National Survey," 2011. Retrieved December 23, 2017 http://www.audiencescapes.org/sites/default/files/Audienc eScapes_Tanzania_Health_Communication_Montez.pdf

[43] N. Mosha, S. Sulemani, "Health Information Needs and Health Information Seeking Behavior Among Small Farmers at Kilimanjaro Region-Tanzania," Scholarly Journal of Medicine, 2012, 2(6), 77-83.

\section{Authors' Profiles}

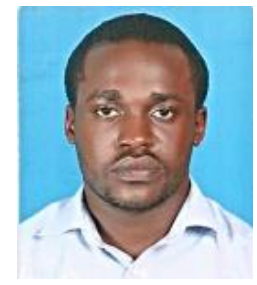

Ibrahim A. Mwammenywa is an ICT specialist and researcher in the ICT fields particularly in electronic health (e-health) and mobile applications. Currently, he is pursuing Master's Degree in Information and Communications Science and Engineering (ICSE) at the Nelson Mandela - African Institution of Science and Technology (NM-AIST).

He received his Bachelor's Degree in Telecommunications Engineering in 2014 at the University of Dar es Salaam (UDSM) and in the same year being registered by the Engineering Registration Boards (ERB) of Tanzania as a graduate engineer. $\mathrm{He}$ then worked with the state-owned telecommunications company, Tanzania Telecommunication Company Limited (TTCL); before joined the UDSM to work as the academician in December 2015.

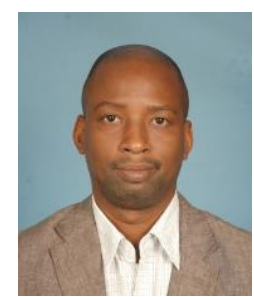

Shubi F. Kaijage obtained his Doctor of Engineering degree (Electronics and Information Eng.) from University of the Ryukyus, Okinawa, Japan, in March 2011. Since February 2014, he has been working with Nelson Mandela African Institution of Science and Technology (NM-AIST), Tanzania, in the school of Computational and Communication Science and Engineering (CoCSE), From September 2011 to December 2013.

He has vast experience of over 8 years of research in the areas of fiber optics, photonics and Terahertz technology, wireless sensor network \& RFID technologies. He worked as a Post-Doctoral Research Fellow at the Research Center of Terahertz Technology, Shenzhen University, P. R. China. He has published over 30 scientific papers in International peerreviewed journals and over 50 research works presented in various International conferences and workshops. Furthermore, he is a recipient of numerous International awards and grants as recognition to his scholarly works.

Shubi is the member of International professional societies including the Institute of Electrical and Electronics Engineering (IEEE), African Academy of Sciences (AAS), and the Optical Society of America (OSA).

How to cite this paper: Ibrahim A. Mwammenywa, Shubi F. Kaijage, "Towards Enhancing Access of HIV/AIDS Healthcare Information in Tanzania: Is a Mobile Application Platform a Way Forward?", International Journal of Information Technology and Computer Science(IJITCS), Vol.10, No.7, pp.31-38, 2018. DOI: 10.5815/ijitcs.2018.07.04 